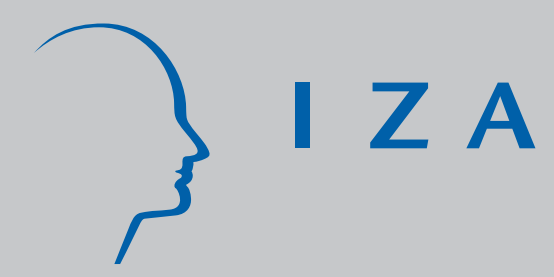

IZA DP No. 2520

Relative Efficiency, Scale Effect, and Scope Effect of Public Hospitals: Evidence from Australia

Jian Wang

Zhong Zhao

Amir Mahmood

December 2006 


\title{
Relative Efficiency, Scale Effect, and Scope Effect of Public Hospitals: Evidence from Australia
}

\author{
Jian Wang \\ Shandong University, China \\ Zhong Zhao \\ IZA Bonn, Germany \\ Amir Mahmood \\ University of Newcastle, Australia
}

Discussion Paper No. 2520

December 2006

IZA

P.O. Box 7240

53072 Bonn

Germany

Phone: +49-228-3894-0

Fax: +49-228-3894-180

E-mail: iza@iza.org

\begin{abstract}
Any opinions expressed here are those of the author(s) and not those of the institute. Research disseminated by IZA may include views on policy, but the institute itself takes no institutional policy positions.

The Institute for the Study of Labor (IZA) in Bonn is a local and virtual international research center and a place of communication between science, politics and business. IZA is an independent nonprofit company supported by Deutsche Post World Net. The center is associated with the University of Bonn and offers a stimulating research environment through its research networks, research support, and visitors and doctoral programs. IZA engages in (i) original and internationally competitive research in all fields of labor economics, (ii) development of policy concepts, and (iii) dissemination of research results and concepts to the interested public.
\end{abstract}

IZA Discussion Papers often represent preliminary work and are circulated to encourage discussion. Citation of such a paper should account for its provisional character. A revised version may be available directly from the author. 
IZA Discussion Paper No. 2520

December 2006

\section{ABSTRACT \\ Relative Efficiency, Scale Effect, and Scope Effect of Public Hospitals: Evidence from Australia}

Using the 1997-1998 New South Wales public-hospitals comparison data, we investigate the hospital-level inefficiency by applying a stochastic-frontier multiproduct cost function. We use a flexible translog cost function to reduce the measurement errors of the outputs of the hospital. The main findings are: First, inefficiency accounts for $9.3 \%$ of total hospital costs in large hospitals and $11.3 \%$ in small hospitals, when including complexity indicators. Second, diseconomies of scale exist in very large hospitals, whereas scale economies appear in very small hospitals. Third, scope effects are found in both large and small hospitals. Fourth, small hospitals are more labor-intensive than large hospitals are.

JEL Classification: I11, I18, C31

Keywords: translog cost function, economies of scale and scope, efficiency, public hospital

Corresponding author:

Zhong Zhao

IZA

P.O. Box 7240

D-53072 Bonn

Germany

E-mail: zhao@iza.org 


\section{Introduction}

Economists and policymakers are always interested in efficiency, especially as related to performance in the public sector. The purpose of this paper is to study the efficiency of public hospitals. Using the 1997-1998 New South Wales public-hospitals comparison data, we study the relative efficiency and performance of public hospitals in New South Wales (NSW), Australia.

The escalating cost of health services in Australia has prompted the government and other hospital funding agencies in NSW to increase their efforts in monitoring and planning of hospital service provision over the last decade. Nonetheless, because there are two levels of government in NSW responsible for health-care policy, funding decisions, and hospital care regulations, the non-market factors make some of the hospitals consistently earn positive profits and therefore have little incentive to expand their capacity and to attract more patients, or to remove their excess capacity and staff (Palmer and Short, 1994).

The intent of this paper is to address both hospital structure and hospital-level efficiency. Applying a stochastic-frontier multiproduct cost function, we can study relative efficiency at the hospital level. This approach also allows us to test whether there are scale effects and scope effects.

In the literature, measuring the output of a hospital is always difficult because a hospital's true final output, improvement in the health of patients, is unobservable. Researchers have been using measures of throughputs or intermediate outputs, such as the number of cases treated, number of patient-days served per hospital department, and number of outpatient consultations, to proxy for the true output. However, this strategy raises a set of problems related to the heterogeneity of hospital outputs. Two aspects of the heterogeneity that have attracted widespread attention are the case mix and the quality of care. In order to mitigate this problem, 
we use a flexible translog cost function, which includes direct measures of inpatient case mix and hospital complexity indicators to reduce the measurement errors of the output of hospitals. ${ }^{1}$

The main findings in this paper are: First, inefficiency accounts for 9.3\% of total hospital costs in large hospitals, and $11.3 \%$ in small hospitals, controlling for complexity indicators. Second, diseconomies of scale exist in very large hospitals, whereas scale economies appear in very small hospitals. Third, scope effects are found in both large and small hospitals. Fourth, small hospitals are more labor-intensive than large hospitals are.

The remainder of the paper is organized as follows. Section 2 outlines the stochasticfrontier multiproduct cost-function approach. Section 3 describes the data set and the variables used in the paper. That section also discusses the empirical issues in estimating a hospital cost function. Section 4 gives the empirical results and the policy implications. Section 5 concludes the paper.

\section{Analytical Framework}

There are two main methods to estimate relative efficiency. One is data envelopment analysis approach, which evaluates the relative efficiency by comparing each producer with the best producer. The other is the stochastic-frontier multiproduct cost-function approach, which calculates an efficiency score for each individual producer. Based on the score, the inefficient producer(s) can be identified.

This paper applies the stochastic-frontier multiproduct cost-function approach with translog specification. The advantage of stochastic-frontier approach is that if the data are from those hospitals that minimize their cost for given level of outputs, input prices, and fixed factors, and if

\footnotetext{
${ }^{1}$ Scott and Parkin (1995) investigate the role of translog cost function in estimating the hospitals efficiency.
} 
the specification of the cost function is flexible enough, this approach can identify the "true" structure of the variable-cost function through the estimation process, provided that the list of regressors is complete. ${ }^{2}$ However, the results may not be valid globally (Vita, 1990).

Since Christensen et al. (1973) and Brown et al. (1979), the specification of the cost function has usually been in translog form because of its flexibility and its having fewer parameters than some other flexible functional forms. For $n$ outputs and $m$ inputs, the translog cost function has $(m+n)(m+n+1) / 2$ parameters (see Brown et al., 1979).

Given $I$ variable inputs, $T$ fixed factors, and $N$ outputs, a variable-cost function with a transcendental logarithmic specification has the form

$$
\begin{aligned}
\ln c^{\nu *}= & \alpha_{O^{+}} \sum_{i=1}^{I} \alpha_{I} \ln w_{i}^{*+}+\sum_{n=1}^{N} \beta_{n} \ln y_{n}{ }^{*}+\sum_{t=1}^{T} \gamma_{t} \ln k_{t}^{*} \\
& +\frac{1}{2} \sum_{i=1}^{I} \sum_{j=1}^{I} \alpha_{i j} \ln w_{i}^{*} \ln w_{j}^{*}+\frac{1}{2} \sum_{n=1}^{N} \sum_{m=1}^{N} \beta_{n m} \ln y_{n}{ }^{*} \ln y_{m}{ }^{*+} \frac{1}{2} \sum_{t=1}^{T} \sum_{s=1}^{T} \gamma_{t s} \ln k_{t}^{*} \ln k_{s}^{*} \\
& +\sum_{i=1}^{I} \sum_{n=1}^{N} \rho_{i n} \ln w_{i}^{*} \ln y_{n}{ }^{*}+\sum_{i=1}^{I} \sum_{t=1}^{T} \delta_{i t} \ln w_{i}{ }^{*} \ln k_{t}^{*}+\sum_{n=1}^{N} \sum_{t=1}^{T} \theta_{n t} \ln y_{n}{ }^{*} \ln k_{t}^{*}+\xi x+v+u
\end{aligned}
$$

where $\ln c^{\nu *}, \ln w_{i}^{*}$ for $i=1, \ldots, I, \ln y_{n}{ }^{*}$ for $n=1, \ldots, N$, and $\ln k_{t}^{*}$ for $t=1, \ldots, T$ are the natural logarithms of the mean-scaled values of the variable costs, input prices, output levels, and fixed factors, respectively; $x$ is a vector of hospital complexity indicators; $v$ is the measurement errors of output variables; and $u$ is other random factors. Aiger et al. (1977) assumed that $v$ is an independently and identically distributed (i.i.d.) normal variable with mean 0 and variance $\sigma_{v}{ }^{2}$, and $u$ is an i.i.d. half-normal random variable.

\footnotetext{
${ }^{2}$ A recent review on this literature can be found in Worthington (2004).
} 
To be a well-behaved cost function, equation (1) must be linearly homogeneous and concave in factor prices, convex in output levels, and nondecreasing and continuous in both output levels and factor prices. Mathematically, we have following restrictions:

$$
\begin{aligned}
& \alpha_{i j}=\alpha_{j i} \quad \text { for all } i \text { and } j \\
& \beta_{n m}=\beta_{m n} \quad \text { for all } n \text { and } m \\
& \sum_{i=1}^{I} \alpha_{i}=1, \quad \sum_{j=1}^{I} \alpha_{i j}=0, \quad i=1,2, \ldots, I \\
& \sum_{i=1}^{I} \rho_{i n}=0, \quad n=1,2, \ldots, N \\
& \sum_{i=1}^{I} \delta_{i t}=0, \quad t=1,2, \ldots, T \\
& s_{i}=\alpha_{i} \geq 0, \quad i=1,2, \ldots, I \\
& \partial \ln c^{v} / \partial \ln y_{n}=\beta_{i j} \geq 0, n=1,2, \ldots, N
\end{aligned}
$$

where $s_{i}=w_{i}{ }^{*} \chi_{i} / c^{\nu^{*}}$ is the share of the ith input in variable costs.

Equations (2) and (3) ensure continuity in factor prices and output levels. Equations (4) to (6) are from linear homogeneity (or constant returns to scale). Equations (7) and (8) are from monotonicity in factor prices and in output levels. These inequalities hold at the sample means.

Using Shepherd's lemma, we have the following additional restrictions, usually called input share equations:

$$
\partial \ln c^{v^{*}} / \partial \ln w_{i}^{*}=s_{i}=\alpha_{i}+\sum_{j=1}^{I} \alpha_{i j} \ln w_{j} *+\sum_{n=1}^{N} \rho_{i n} \ln y_{n} *+\sum_{i=1}^{T} \delta_{i t} \ln k_{t} * \quad \text { for } i=1,2, \ldots, I
$$

Imposing these share equations can improve efficiency as well as circumvent the degree-offreedom problem when the sample size is small. The above model can be estimated by seemingly 
unrelated least-squares regression (SUR). Since the cost shares must sum to 1 , one of the costshare equations has to be deleted in estimation.

\section{Data Set and Empirical Issues}

The data set used in this paper is the NSW public-hospitals comparison data (PHCD) for the 1997-1998 fiscal year. There are 114 acute public hospitals in the data. Based on the size and complexity of the hospitals, we classify them as large hospitals and small hospitals. Large hospitals include principal referral, specialist pediatric, ungrouped acute, major metropolitan, and major nonmetropolitan hospitals. Small hospitals are district hospitals.

The main variables are the total variable cost, average salary of medical labor services, average salary of nonmedical labor services, inpatient service index, occasions of services, average available beds, same-day separations as a percentage of total separations, average length of stay for acute episodes, and so on (see Table 1).

When estimating a stochastic-frontier function for a hospital, there are several difficulties related to case mix, aggregation of throughputs, and measurement of hospital output.

Labor is a predominant input of hospitals. Our data set contains aggregate wage indices for medical staff and supporting staff separately. We define variable costs as the total expenditure on both medical and nonmedical labor services in a hospital. Annual salary is calculated for two categories of labor inputs: (1) medical and visiting medical officers, and (2) nonmedical labor inputs such as nurses, other personal care staff, administrative and clerical staff, diagnostic and allied health staff, domestics, etc.

The input price of a salaried medical officer is defined as the total annual salary of all medical officers divided by the number of equivalent full-time medical officers. The salaries of 
medical officers and visiting medical officers account for $15.3 \%$ of total expenditure for large hospitals and $14.2 \%$ for the small ones. The salaries of nonmedical officers are $43.9 \%$ of the total expenditures for large hospitals and $42.9 \%$ for small ones.

Other major inputs are general materials and supplies. Unfortunately, we have no information on these. However, given the purchasing power of most hospitals, it is reasonable to assume that the price of materials is the same across hospitals. Other expenses, including those for superannuation, drug supplies, medical and surgical supplies, food, domestic services, repair and maintenance, patient transportation, administration, depreciation, and other nonsalary, are assumed quasi-fixed.

For a hospital, a case refers to a situation exhibiting a variety of illness that is treated in a hospital setting.

When estimating cost functions, we have two difficulties.

One difficulty is that if hospitals do not administer the same kind of ailments (or if they follow radically different treatment protocols), then their productions and costs are bound to be different. These hospitals ought not to be treated as belonging to the same class of firms.

The number of diseases and conditions for which patients seek treatment is large. Some form of aggregation of the hospital throughputs is necessary to avoid running out of degrees of freedom. Unfortunately, what is the best method to aggregate is still an unsettled issue; there is no shortage of proposals in the literature.

Breyer (1987) suggests handling the case mix by grouping patients into an arbitrary (manageable) number of diagnostic categories and by specifying that each diagnostic group raises total costs only by a constant. Wagstaff and Barnum (1992) note that Breyer's approach assumes away the possibility of economies of scope. The usual technique to aggregate hospital 
throughputs is to include a case-mix index in the hospital cost function (Ellis, 1992). Ellis cautions since diagnosis-related group (DRG) costs are designed to measure the cost of hospital resources used in each diagnostic group, the case-mix index commingles output variables with measures of inputs.

The other difficulty is that the correct specification of the cost function requires all outputs of hospitals to be included as regressors.

Breyer (1987) argues that the true output of a hospital is the improvement in patients' health. Defined in this way, output is impossible to measure. Breyer recommends using observable intermediate products as proxies for output. In particular, he suggests three important hospital intermediate outputs: number of cases (as a proxy for medical services), number of inpatient days (as a proxy for nursing, accommodation, and other "hotel” services), and number of beds.

Like the case-mix problem, quality of care has not been satisfactorily dealt with in the empirical literature. As Ellis (1992) points out, hospitals with higher mortality rates and readmission rates ought not to be regarded as having the same outputs as those with lower rates. Yet this kind of misspecification is exactly what happens when quality of care is not controlled for in the cost function. By using only throughputs as measures of hospital outputs, one will miss vital information on the effectiveness of treatments. Some measures of quality that have been proposed or used in the literature are: the teaching status of hospitals, the number or proportion of specialists on the medical staff, the location and accessibility of the hospital, the prevalence of 
amenities (e.g., cleanliness of facilities, hospitality of the staff, and quality of food), and the occupancy rate of hospitals. ${ }^{3}$

Our measures of hospital output are an index for the number of inpatient services, and one for the number of occasions of service (OOS). We construct a case-mix index following Vita (1990) and Grannemann et al. (1986). They recognize there are two ways that a hospital can produce more days of care. It either can increase admission, holding average length of stay constant, or can increase length of stay, holding admission constant. Thus, relationships between separation and average length of stay for all the inpatient activities need to be included in the cost function. ${ }^{4}$ Following Dor and Farley (1996), we calculate inpatient service index as follows:

$$
M_{h}=\sum_{d} \frac{X_{d h}}{X_{h}} \overline{S_{d}}
$$

where

$X$ is the number of separations

$h$ is a dummy indicator of large or small hospital

$d$ is an index for the diagnostic category (AN-DRGs, ${ }^{5}$ version 3.1)

$\overline{S_{d}}$ is a weight corresponding to the average length of stay for separations with conditions given by indices of the diagnostic category.

We use AN-DRG-weighted separations and corresponding average lengths of stay as measures of the output or quality of the hospital. Therefore, $M_{h}$ can be appropriately defined to capture the usage of hospital resources. We use OOS as our proxy for outpatient care, since there is no better alternative information in the data.

\footnotetext{
${ }^{3}$ The occupancy rate of hospitals was used by Friedman and Pauly (1981) as a measure of quality, on the argument that as admissions approach the hospital's full capacity, the resources of the hospitals have to be spread more thinly, and this results in lower quality overall.

${ }^{4}$ Separation is used here to refer to the general admissions.

${ }^{5}$ Australian National Diagnosis-Related Groups.
} 
Notwithstanding the above issues, estimating hospital cost functions has generally proceeded under the assumption that hospitals are a class of multiproduct firms whose common objective is to minimize cost subject to an output constraint. We also adopt the cost-minimizing assumption, for the following reasons: first, public acute hospitals are nonprofit organizations in NSW, and therefore these hospitals have objectives other than profit maximization; second, cost minimization is a necessary condition for profit- and budget-constrained output maximization and therefore a legitimate objective under a wide variety of circumstances; third, it is contended that hospitals do not exercise monopolistic powers over inputs.

\section{Results and Sensitivity Analysis}

\section{Empirical Results}

Table 2 and Table 3 are estimates of translog variable cost functions for small hospitals and for large hospitals, respectively.

Cost Share and Cost Elasticity of Outputs. The input price coefficients are the intercepts of the cost-share equations. Since the variables in the translog variable cost function are meanscaled, when the share equations are evaluated at the sample means, the coefficients also represent the cost shares of the various input categories. So the coefficients of input prices $\left(\alpha_{i}^{\prime}\right.$ s $)$ must lie in the unit interval.

In small hospitals, nonmedical labor input has the highest estimated share of variable costs (64.8\% with a 5\% statistical significance level), and medical labor input accounts for the remaining 35.2\%. In large hospitals, nonmedical labor input accounts for $80.7 \%$ of variable cost with $1 \%$ significance level, and medical labor input accounts for $19.3 \%$. These results suggest that small hospitals are more labor-intensive than large hospitals. 
The coefficients of outputs can be interpreted as the output elasticity of variable costs (which are monotonic transformations of marginal costs) evaluated at the sample means. The lack of statistical significance of $\hat{\beta}_{1}$ and the significant but small magnitude of $\hat{\beta}_{2}$ indicate that the variable cost is fairly unresponsive to small increases in outputs. For instance, $\hat{\beta}_{2}=0.298$ for small hospitals implies that if the number of OOSs of a hospital doubled, variable costs would increase only about $29.8 \%$ on average. This can happen on the declining portion of the standard textbook short-run average-cost curve.

Economies of Scale. An important application of hospital cost functions is testing for economies of scale. For multiple-output firms, the most commonly used concept of economies of scale is the ray, or overall, economy of scale, which measures the response of total cost to a proportional change in all output categories, holding all other variables constant at their means. ${ }^{6}$ For a translog variable-cost function, this translates to

$$
\varepsilon=\frac{1-\left[\sum_{t=1}^{T}\left(\gamma_{t}+\gamma_{t t} \ln k_{t}^{*}+\sum_{i=1}^{I} \delta_{i t} \ln w_{i}^{*}+\sum_{n=1}^{N} \theta_{n t} \ln y_{n}^{*}\right)+\frac{1}{2} \sum_{t=1}^{T-1} \sum_{s=t+1}^{T} \gamma_{t s} \ln k_{s}^{*} \cdot\right]}{\sum_{n=1}^{N}\left(\beta_{n}+\beta_{n n} \ln y_{n}^{*}+\sum_{i=1}^{I} \rho_{i n} \ln w_{i}^{*}+\sum_{t=1}^{T} \theta_{n t} \ln k_{t}^{*}\right)+\frac{1}{2} \sum_{n=1}^{N-1} \sum_{m=n+1}^{N} \beta_{n m} \ln y_{m}^{*}}
$$

where $k_{t}^{* \prime}$ and $k_{s}^{* \prime}$ are the mean-scaled long-run optimal levels of the tth and sth fixed inputs. Since $\ln w_{i}^{*}=\ln y_{n}^{*}=\ln k_{t}^{*}=0$ for all $i, n$, and $t$ at the point of approximation, the index of ray scale economies at that point is reduced to the following, where it is evaluated at the sample means:

\footnotetext{
${ }^{6}$ Cowing et al. (1983) note that when the firm's scale of operation is expanded, outputs along the same ray are not always on the firm's least-cost path.
} 


$$
\in=\frac{1-\left(\sum_{t=1}^{T} \gamma_{t}+\sum_{t=1}^{T} \gamma_{t t} \ln k_{t}^{*{ }^{\prime}+}+\frac{1}{2} \sum_{t=1}^{T-1} \sum_{s=t+1}^{T} \gamma_{t s} \ln k_{s} *^{\prime \prime}\right)}{\sum_{n=1}^{N} \beta_{n}}
$$

Economies of scale exist if $\varepsilon>1$. Each hospital should expand its operation when economies of scale exist in the short run. When $\varepsilon<1$, diseconomies of scale exists.

Do average variable costs decline, increase, or keep pace with outputs if hospitals expand the scale of their operation (while maintaining the relative proportions of their outputs)? This question can be answered using the index of ray scale economies $\varepsilon$ at the long-run optimum level of fixed input. For $T=1$ and $N=2$, the ray scale is

$$
\epsilon=\frac{1-\left(\hat{\gamma}_{1}+\hat{\gamma}_{11} \ln k_{1} *^{\prime}\right)}{\sum_{n=1}^{2} \hat{\beta}_{n}}=\frac{1-\left(0.450+0.5 \ln k_{1} *^{\prime}\right)}{0.220+0.298}
$$

The value of $\varepsilon$ depends on $k^{* \prime}$, the mean-scaled long-run optimal number of hospital beds, which unfortunately is unknown. But $k^{* \prime}$ can be solved for if $\varepsilon=1$ to derive relative ranges of economies or diseconomies of scale. Using the sample mean for small numbers of hospital beds (40), we have

$$
\varepsilon\left\{\begin{array}{l}
> \\
= \\
<
\end{array}\right\} \text { when } \quad k^{* \prime}\left\{\begin{array}{l}
< \\
= \\
>
\end{array}\right\} 42.6
$$

Similarly, for large hospitals,

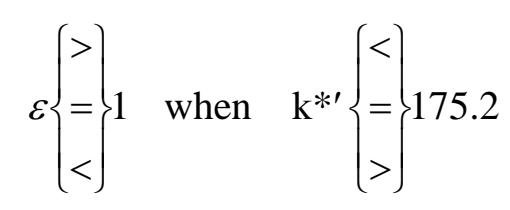

Very small hospitals $\left(k^{* \prime}<<43\right)$ may exhibit economies of scale, while very large hospitals $\left(k^{* \prime}\right.$ >> 175) may exhibit diseconomies of scale 
Economies of Scope. For a multiple-product firm, economies of scope exist if the outputs produced jointly are cheaper than the outputs produced separately. Formally, scope economies exist if

$C\left(y_{1}, y_{2}, \ldots, y_{N}\right)<c\left(y_{1}, 0, \ldots, 0\right)+c\left(0, y_{2}, \ldots, 0\right)+\ldots+c\left(0,0, \ldots, y_{N}\right)$

Diseconomies of scope can be defined in a similar way; that is, outputs when produced jointly are more expensive than when produced separately.

With a translog variable-cost function, the condition for scope economies is simplified to

$$
C_{n m}=\beta_{n m}+\beta_{n} \beta_{m}<0 \quad \text { for } n \neq m
$$

Hospital output categories that are cheaper to produce jointly should be available in one hospital. Hospital outputs that are more expensive to produce jointly should be offered in separate and specialized hospitals.

Should hospitals offer both inpatient and OOS facilities? The index of scope economies for small hospitals is 0.226 , and for large hospitals is 0.184 . Both are significantly different from zero based on the Wald test $\left(x_{\text {small }}{ }^{2}=37.4, x_{\text {large }}{ }^{2}=28.2\right)$. Thus, it is apparently cheaper for both small and large public acute hospitals to offer both inpatient services and OOSs jointly.

Bed Capacity. Given the widespread concern over escalating medical care costs, one issue that has attracted much attention in the hospital cost literature is whether hospitals employ fixed inputs according to their long-run cost-minimizing level. More specifically, we want to investigate whether hospitals have too much capital equipment, since overinvesting in capital equipment is often blamed for cost increases.

Wagstaff and Barnum (1992) argue that the problem is not whether outputs should be expanded to fully utilize the fixed inputs, which is a question of economies of scale, but is whether optimal amounts of fixed inputs are employed given the output levels of hospitals. 
To examine this point, Cowing et al. (1983) propose checking whether $\partial c^{v} / \partial \mathrm{k}$ is statistically different from $-w_{k}{ }^{*}$ or not. If $-\partial c^{v} / \partial k<w_{k}$, then fixed input $k$ is overemployed, since savings in variable costs due to the employment of an additional unit of capital are less than the marginal cost of capital. Otherwise, fixed input $k$ is underemployed

Wagstaff and Barnum (1992) suggest using the following total-cost equation:

$$
c=w^{v} x^{v}+w^{k} k=c^{v}\left(w^{v}, v, k\right)+w^{k} k
$$

If $\hat{w}^{k}=0$ then $\partial c / \partial k_{t}=\partial c^{v}\left(w^{k}, y, k\right) / \partial k_{t}=0$. This implies that the level of the fixed assets employed is consistent with their long-run cost-minimizing levels. If $\hat{w}^{k}>0$, then $\partial c / \partial k_{t}=0>\partial c^{v}\left(w^{k}, y, k\right) / \partial k_{t}$, which suggests that hospitals have underemployed fixed inputs; $\hat{w}^{k}<0$ suggests that hospitals have overemployed fixed inputs

Wagstaff and Barnum's specification may be subject to serious collinearity problems, since the fixed factors enter the specification twice, both as arguments of the variable-cost function $c^{v}$, and as components of the fixed cost $w^{k} k$.

In this paper we use a variable-cost function specification to assess the cost structure of the NSW public hospitals. We estimate a short-run variable-cost function, since the NSW acute public hospitals are regulated. The fixed factors of hospitals, such as beds, have to be commissioned by the NSW Department of Health. Although a hospital manager is able to adjust staff levels rapidly, it takes a considerably longer time to change bed numbers or to construct a new ward. It is unlikely that a hospital is able to choose the optimal fixed factor accordingly. There is no evidence suggesting that hospitals are in long-run equilibrium.

Whether there is too much capital stock in the hospital system given the levels of outputs of hospitals is usually investigated by seeing whether $\partial c / \partial k_{t}<0$ [or equivalently, 
$\left.\partial c^{v}\left(w^{k}, y, k\right) / \partial k_{t}=\gamma<0\right]$, since along the same isoquant, the utilization of variable inputs must decrease as the amount of the fixed factor increases.

For small hospitals, the coefficient of the number of beds is $\hat{\gamma}=0.450$, but is not significant (Table 2). This means that small hospitals are not overcapitalized. In contrast, large hospitals are overcapitalized ( $\hat{\gamma}=0.542$, significant at the $5 \%$ level; see Table 3 ). The result for large hospitals is similar to those of Cowing et al. (1983) and Alba (1995). However, Wagstaff and Burnum (1992) point out that $\partial c / \partial k_{t}>0$ (the partial derivative of total costs with respect to capital stock) does not necessarily indicate overcapitalization. They argue that $\partial c / \partial k_{t}>0$ is instead evidence that variable costs have not been totally rid of fixed costs.

There is also another possible interpretation for $\partial c / \partial k_{t}>0$. When new capital equipment becomes available in hospitals, it may well be that doctors change the procedures and favor using the new machine. If so, variable costs will be positively affected by increasing the hospitals' stock of capital. In other words, it is possible that when a hospital purchases new equipment, it not only increases the capital stock but also changes the hospital's technology.

Technical Inefficiency. Farrell (1957) first introduced the efficiency frontier technique, which is an alternative approach to the regression technique. It tends to take account of outliers. Following Farrell (1957), technical efficiency is defined as the ability of a hospital to obtain maximum output from a given set of inputs. The technical efficiency of the ith firm is defined by $T E_{i}=\exp (u i)$. Once the parameters in equation (1) are estimated, the mean inefficiency can be calculated, since the mean of the stochastic error term $v$ is zero. The mean value of $u$ is then added to the fitted level of cost for each firm $i$. The resulting sum is the predicted value of the total cost $C$. The difference between the predicted $C$ and the observed $C$ is the composite error term $e=u+v$. 
Jondrow et al. (1982) show that the expected value of $u$ for each observation, given the estimated composite error term and the normal or half-normal distribution of $v$ and $u$, is

$$
E\left[u_{i} \mid e_{i}\right]=-\gamma e_{i}+\sigma_{A}\left\{\frac{\phi\left(\gamma e_{i} / \sigma_{A}\right)}{1-\Phi\left(\gamma e_{i} / \sigma_{A}\right)}\right\}
$$

where $\sigma_{A}=\sqrt{\gamma(1-\gamma) \sigma_{S}^{2}}, e_{i}=\ln y_{i}-x_{i} \beta$, and $\phi(\cdot)$ is the standard normal density function.

As in Coelli (1996), we estimate the efficiency with FRONTIER Version 4.1. Table 4 presents the analysis of the effect of model specification on inefficiency scores. The results show that the measured inefficiency is largest when cost is treated solely as a function of output levels and input prices. In this specification, the mean inefficiency is $11.6 \%$ of total costs in small hospitals. Adding output complexity indicators slightly decreases the degree of inefficiency, to 11.3\%. The correlation coefficient $r=0.65$ indicates the estimates from different specifications are highly correlated. It suggests that the model with output complexity indicators is highly correlated with the basic cost function. The basic model specification is appropriate for measuring the inpatient case mix and OOSs with reduced measurement errors.

For large hospitals, the mean inefficiency of the total variable cost is 9.6\% (Table 4). After controlling for hospital complexity, it reduces to 9.3\%. The high correlation coefficient $r=0.851$ indicates that the basic model specification is appropriate for estimating the efficiency of multiproduct hospitals.

Our results are comparable to the ones discussed in Zuckerman et al. (1994), which suggests that the average level of inefficiency across all hospitals is in the range of $10-14 \%$. They also suggest that the stochastic-frontier approach is appropriate for estimating inefficiency over a wide range of scenarios. 


\section{Sensitivity Analysis}

Different specifications of the cost functions are estimated by the SUR and full-information maximum-likelihood methods. We also have tried different forms of variables, such as lognormal and normal-log; have experimented with second-order terms, i.e., squared and interaction terms; and have changed the measurement units of the input prices. The estimates are robust to these different settings.

\section{Conclusions}

The empirical results in this study appear reasonable and consistent with findings in the literature. The variable-cost function is consistent with the theoretical requirements of a cost function. Key coefficient estimates, such as the cost of the share of inputs $\left(\hat{\alpha}_{i}\right)$ and the output elasticity of variable costs $\left(\hat{\beta}_{n}\right)$, have the expected signs with reasonable magnitudes and significance levels.

The estimates of $\gamma_{1}$, the coefficient for beds, are positive and insignificant for small hospitals, but positive and significant for large hospitals. One explanation for this is that small and large hospitals adopt new technology at different speeds when they expand their operations.

We find on average the optimal bed capacity is about 43 beds for small hospitals and 175 beds for large hospitals. This implies that if the scale of hospital operation were doubled, the long-run average cost for small hospitals with fewer than 43 beds would decrease. The same is true for large hospitals with fewer than 175 beds.

Efficiency estimation shows that technical inefficiencies are $11.3 \%$ for small hospitals and 9.3\% for large hospitals after controlling for the complexity indicator. 
However, given the large size of the NSW public hospital sector, and the unique opportunities it affords us for developing and testing econometric models in an environment where nonprice rationing devices dominate, it is important and should be fruitful to carry out further work to explore efficiency and equity issues.

In our future research, we plan to develop a translog variable-cost-function model to explore the issue of distributive efficiency and to decompose the inefficiency into "pure" technical inefficiency and scale inefficiency. 


\section{References}

Aiger, D., Lovell, C.A.K. and Schmidt, P. (1977), "Formulation and Estimation of Stochastic Frontier Production Models”, Journal of econometrics 6, pp. 21-37.

Alba, M. M. 1995, "Estimating a Translog Variable Cost Function for Sixty-Five Hospitals in the Philippines,” a report submitted to the Baseline Studies for Health Care Financing Reform Project. Makati, Metro Manila: Philippines Institute for Development Studies.

Breyer, F., 1987, “The Specification of a Hospital Cost Function, a Comment on the Recent Literature,” Journal of Health Economics, 6: 147-57.

Brown, R. S., Caves, D. W., and Christensen, L. R., 1979, "Modelling the Structure of Cost and Production for Multiproduct Firms,” Southern Economic Journal 46(1): 256-273.

Christensen, L. R., Jorgenson, D. W., and Lau, L. V., 1973, "Transcendental Logarithmic Production Frontiers,” Review of Economics and Statistics 55(1): 28-45.

Coelli, T. J., 1996, “A guide to FRONTIER version 4.1: A Computer Program for Stochastic Frontier Production and Cost Function Estimation,” Centre for Efficiency and Productivity Analysis Working Paper 96/07, University of New England.

Cowing, T. G., Holtmann, A. G., and Powers, S., 1983, “Hospital Cost Analysis: A Survey and Evaluation of Recent Studies, Advances in Health Economics and Health Service Research,” Connecticut: JAI Press.

Dor, Avi and Farley, D. E., 1996, “Payment Source and the Cost of Hospital Care: Evidence from a Multi-product Cost Function with Multiple payers,” Journal of Health Economics 15: $1-21$.

Ellis, R., 1992, “Hospital Cost Function Estimation When Firms May not Try to Minimize Total Costs,” Manuscript, Boston University. 
Farrell, M.J. (1957), “The Measurement of Productivity Efficiency”, Journal of the Royal Statistical Society A CXX, part 3, pp.253-290.

Friedman, Bernard and Pauly, M., 1981, "Cost Functions for a Service Firm with Variable Quality and Stochastic Demand: The Case of Hospitals,” Review of Economic and Statistics 63: 620-24.

Grannemann, T., Brown, R., and Pauly, M., 1986, “Estimating a Hospital Costs: A Multi-Output Analysis,” Journal of Health Economics 5: 107-27.

Jondrow, J. Lovell, C.A.K Materov, I.S. Schmidt, P. (1982), “On the Estimation of Technical Inefficiency in the Stochastic Frontier Production Function Model”, Journal of Econometrics 23, pp.269-274.

Palmer, G. R. and Short, S. D., 1994, "Health Care and Public Policy: An Australian Analysis," $2^{\text {nd }}$ Edition, Melbourne: Macmillan.

Scott, A. and Parkin, D., 1995, "Investigating Hospitals Efficiency in the New NHS: the Role of the Translog Cost Function,” Health Economics 4: 467-78.

Vita, M.G., 1990, “Exploring Hospital Cost Functions with Flexible Functional Forms,” Journal of Health Economics 9: 1-21.

Wagstaff, A. and H. Barnum, 1992, “Hospital Cost Function for Developing Countries,” Policy Research Working Paper Series 1044, Washington, D.C.: World Bank Population and Human Resource Department.

Worthington, Andrew C., 2004, “Frontier Efficiency Measurement in Health Care: A Review of Empirical Techniques and Selected Applications,” Medical Care Research and Review, Vol. 61, No. 2, 135-170. 
Zuckerman, S., Hadley, J., and Iezzoni, L., 1994, “Measuring Hospital Efficiency with Frontier Cost Functions,” Journal of Health Economics 13(3): 255-80. 
Table 1 Definitions and Descriptive Statistics of Variables used in the Analysis

(Input prices are in 1997 financial year Australian dollar)

\begin{tabular}{|c|c|c|c|c|c|}
\hline \multirow[t]{2}{*}{ Variables } & \multirow[t]{2}{*}{ Definitions } & \multicolumn{2}{|c|}{ Mean } & \multicolumn{2}{|c|}{ Standard deviation } \\
\hline & & $\begin{array}{c}\text { Small } \\
\text { hospitals }\end{array}$ & $\begin{array}{c}\text { Large } \\
\text { hospitals }\end{array}$ & $\begin{array}{l}\text { Small } \\
\text { hospitals }\end{array}$ & $\begin{array}{l}\text { Large } \\
\text { hospitals }\end{array}$ \\
\hline Cost (000’s) & Total variable (operation) costs & 5115.37 & 53666.69 & 349.23 & 347685.74 \\
\hline \multicolumn{6}{|l|}{ Input prices } \\
\hline Average salary of medical labor services & Average salary of medical officer and visiting medical officers & 238106.22 & 343948.42 & 218.81 & 149.93 \\
\hline Average salary of non-medical labor services & Average salary of non-medical labor input & 45437.20 & 42921.27 & 6224.37 & 2521.21 \\
\hline \multicolumn{6}{|l|}{ Hospital outputs } \\
\hline Inpatient Service index & $\begin{array}{l}\text { The proportion of a hospital's separations times a weight } \\
\text { corresponding to the average length of stay of separations with } \\
\text { AN-DRG category }\end{array}$ & 4.77 & 5.69 & 2.15 & 1.69 \\
\hline Occasion of Services & $\begin{array}{l}\text { The number of occasions on which one or more health care } \\
\text { professionals provides a service to a non-inpatient. }\end{array}$ & 24533.52 & 259027.00 & 22084.50 & 210333.10 \\
\hline Average available beds & $\begin{array}{l}\text { The number of beds available in the hospital excluding beds in } \\
\text { CRCs on any one day of the year. }\end{array}$ & 40.82 & 260.06 & 19.79 & 189.35 \\
\hline Same day seps \% total seps & The proportion of all separations at the same day. & 25.01 & 39.36 & 10.32 & 8.53 \\
\hline ALOS of acute episodes & $\begin{array}{l}\text { The average length of stay for all acute separations excluding } \\
\text { same day patients. }\end{array}$ & 4.74 & 5.36 & 0.79 & 0.94 \\
\hline Cost per Outpatient OOS (Program 2.3) & $\begin{array}{l}\text { The average cost of an occasion of service provided under the } \\
\text { Outpatient Services program }\end{array}$ & 101.10 & & 72.63 & \\
\hline Cost per emergency OOS (3.1) & $\begin{array}{l}\text { The average cost of an occasion of service provided under the } \\
\text { Emergency Services program (3.1) }\end{array}$ & & 120.43 & & 37.47 \\
\hline Presentations to emergency department & $\begin{array}{l}\text { Presentations are reported in admitted, non-admitted and did } \\
\text { not wait categories. }\end{array}$ & & 26511.81 & & 9729.26 \\
\hline
\end{tabular}

Source: NSW Public Hospitals Comparison Data - 1997/98 
Table 2 Translog Variable Cost Function for Small Hospitals

\begin{tabular}{|c|c|c|c|}
\hline Variables & Parameters & Estimates & t-stat \\
\hline District Group1 & & 0.02 & 0.32 \\
\hline District Group2 & & 0.01 & 0.24 \\
\hline Community Acute & & 0.001 & 0.18 \\
\hline Constant & $\alpha_{0}$ & 0.17 & 0.95 \\
\hline In(Salary of Salaried Medical Officers \& Visiting Medical Officers) & $\alpha_{1}$ & 0.35 & 1.34 \\
\hline ln(Salary of Non Medical Labour Inputs) & $\alpha_{2}$ & 0.65 & $2.46^{*}$ \\
\hline $\ln ($ Case-mix Inpatient Index)] & $\beta_{1}$ & 0.22 & 0.92 \\
\hline $\ln ($ Total Occasions of Service (OOS)) & $\beta_{2}$ & 0.3 & $3.25 * *$ \\
\hline ln(Average Available Beds) & $\gamma_{1}$ & 0.45 & 1.85 \\
\hline $\ln \left[(\text { Salary of Medical Officers \& Visiting Medical Officers })^{2}\right]$ & $\alpha_{11}$ & -0.15 & -1.37 \\
\hline $\ln \left[(\text { Salary of Non Medical Labour Inputs })^{2}\right]$ & $\alpha_{22}$ & -6.39 & -1.18 \\
\hline $\ln \left[(\text { In-patient case-mix Index })^{2}\right]$ & $\beta_{11}$ & 0.28 & 0.68 \\
\hline $\ln \left[(\text { Total Occasions of Service }(\mathrm{OOS}))^{2}\right]$ & $\beta_{22}$ & 0.14 & 1.92 \\
\hline 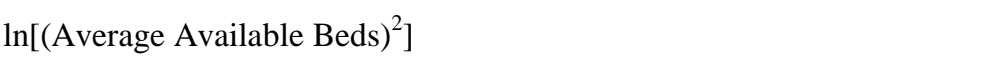 & $\gamma_{11}$ & 0.25 & 0.75 \\
\hline ln(Salary of Medical Officers \& Visiting Medical & $\alpha_{12}$ & 0.15 & 1.37 \\
\hline \multicolumn{4}{|l|}{ Officers) * $\ln ($ Salary of Non Medical Labour Input) } \\
\hline $\ln ($ In-patient case-mix Index $) * \ln (($ Total Occasions of Service (OOS)) & $\beta_{12}$ & 0.16 & 1.15 \\
\hline $\ln$ (Salary of Medical Officers \& Visiting & $\rho_{11}$ & 0.06 & 0.48 \\
\hline \multicolumn{4}{|l|}{ Medical Officers) $* \ln ($ In-patient case-mix Index) } \\
\hline ln(Salary of Medical Officers \& Visiting Medical & $\rho_{12}$ & -0.06 & -0.48 \\
\hline \multicolumn{4}{|l|}{ Officers) $* \ln (($ Total Occasions of Service (OOS )) } \\
\hline $\ln ($ Salary of Non Medical Labour Inputs * $\ln ($ In-patient case-mix Index) & $\rho_{21}$ & -0.84 & -1.17 \\
\hline $\ln ($ Salary of Non Medical Labour Inputs) $* \ln (($ Total Occasions of & $\rho_{22}$ & 0.84 & 1.17 \\
\hline ln(Salary of Medical Officers \& Visiting Medical & $\delta_{11}$ & -0.14 & -0.346 \\
\hline \multicolumn{4}{|l|}{ Officers) $* \ln$ (Average Available Beds) } \\
\hline $\ln ($ Salary of Non Medical Labour Inputs) * $\ln ($ Average Available Beds) & $\delta_{21}$ & 0.14 & 0.34 \\
\hline $\ln ($ In-patient case-mix Index) $* \ln ($ Average Available Beds) & $\theta_{11}$ & -0.83 & -1.18 \\
\hline $\ln ($ Total Occasions of Service (OOS)) * $\ln ($ Average Available Beds) & $\theta_{21}$ & -0.16 & -0.67 \\
\hline ln(Same Day separations \% Total Separations) & & 0.45 & $2.59 *$ \\
\hline $\ln ($ ALOS of Acute Episode) & & -0.6 & -1.77 \\
\hline $\ln (($ Cost per Outpatient (program 2.3)) & & 0.08 & 1.03 \\
\hline $\mathrm{R}^{2}$ & & 0.95 & \\
\hline Log-likelihood Function & & 351.43 & \\
\hline Number of Observations & & 52 & \\
\hline
\end{tabular}

Note: *Significant at $5 \%$ level

$* *$ Significant at $1 \%$ level 
Table 3 Translog Variable Cost Function for Large Hospitals

\begin{tabular}{|c|c|c|c|}
\hline Variables & Parameters & Estimates & t-stat \\
\hline Ungroup acute & & 0.10 & 1.57 \\
\hline Major metropolitan & & 0.10 & 1.16 \\
\hline Major nonmetropolitan & & 0.02 & 1.10 \\
\hline Constant & $\alpha_{0}$ & 0.26 & 1.21 \\
\hline In(salary of salaried medical officers \& visiting medical officers) & $\alpha_{1}$ & 0.19 & 1.07 \\
\hline ln(salary of nonmedical labor inputs) & $\alpha_{2}$ & 0.81 & $4.50 * *$ \\
\hline $\ln ($ case-mix inpatient index) & $\beta_{1}$ & 0.27 & 0.99 \\
\hline $\ln [$ total occasions of service (OOS)] & $\beta_{2}$ & 0.28 & $2.68 * *$ \\
\hline $\ln$ (average available beds) & $\gamma_{1}$ & 0.54 & $2.03^{*}$ \\
\hline$\left[\ln \left[(\text { salary of medical officers \& visiting medical officers })^{2}\right]\right.$ & $\alpha_{11}$ & 0.06 & 0.45 \\
\hline $\ln \left[(\text { salary of nonmedical labor inputs) })^{2}\right]$ & $\alpha_{22}$ & -2.94 & -0.39 \\
\hline $\ln \left[(\text { inpatient case-mix index })^{2}\right]$ & $\beta_{11}$ & 0.66 & 1.49 \\
\hline $\ln \left[\right.$ total occasions of service $\left.(\mathrm{OOS})^{2}\right]$ & $\beta_{22}$ & 0.06 & $3.428^{* *}$ \\
\hline $\ln \left[(\text { average available beds })^{2}\right]$ & $\gamma_{11}$ & 0.25 & 1.29 \\
\hline In(salary of medical officers \& visiting medical & $\alpha_{12}$ & -0.06 & -0.45 \\
\hline \multicolumn{4}{|l|}{ officers) $* \ln ($ salary of nonmedical labor input) } \\
\hline $\ln ($ inpatient case-mix index) $* \ln [$ (total occasions of service $(\mathrm{OOS})]$ & $\beta_{12}$ & 0.11 & 0.59 \\
\hline $\ln ($ salary of medical officers \& visiting medical officers) $* \ln ($ inpatient & $\rho_{11}$ & 0.01 & 0.08 \\
\hline $\ln ($ salary of medical officers \& visiting medical & $\rho_{12}$ & 0.00 & -0.08 \\
\hline \multicolumn{4}{|l|}{ officers) * $\ln [$ (total occasions of service (OOS)] } \\
\hline $\ln ($ salary of nonmedical labor inputs * $\ln ($ inpatient case-mix index) & $\rho_{21}$ & 0.48 & 1.66 \\
\hline $\ln ($ salary of nonmedical labour inputs) $* \ln [$ (total occasions of service & $\rho_{22}$ & -0.48 & -1.66 \\
\hline $\ln ($ salary of medical officers \& visiting medical & $\delta_{11}$ & -0.25 & $-2.17 *$ \\
\hline \multicolumn{4}{|l|}{ officers) $* \ln ($ average available beds) } \\
\hline In(salary of nonmedical labor inputs) $* \ln ($ average available beds) & $\delta_{21}$ & 0.25 & $2.17^{*}$ \\
\hline $\ln ($ inpatient case-mix index $) * \ln ($ average available beds) & $\theta_{11}$ & -0.43 & -1.73 \\
\hline $\ln [$ total occasions of service $(\mathrm{OOS})] * \ln ($ average available beds) & $\theta_{21}$ & -0.15 & -2.02 \\
\hline ln(same-day separations \% total separations) & & 0.25 & $2.112^{*}$ \\
\hline $\ln ($ ALOS of acute episode) & & -0.45 & -1.25 \\
\hline $\ln [($ cost per outpatient (Program 2.3)] & & 0.16 & 1.73 \\
\hline$R^{2}$ & & 0.96 & \\
\hline Log-likelihood function & & 374.43 & \\
\hline Number of Observations & & 61.00 & \\
\hline
\end{tabular}

Note: *Significant at $5 \%$ level

**Significant at $1 \%$ level 
Table 4 Impact of Model Specifications on Measurement of Inefficiency

\begin{tabular}{lcccc}
\hline \hline \multirow{2}{*}{ Model Specifications } & \multicolumn{2}{c}{ Mean Inefficiency } & \multicolumn{2}{c}{ Correlation } \\
\cline { 2 - 5 } & Small Hospital & Large Hospital & Small Hospital & Large Hospital \\
\hline Basic cost function & 12.6 & 9.8 & & 0.73 \\
Basic cost function with complexity & 11.3 & 9.3 & 0.65 & 0.3 \\
\hline
\end{tabular}

